\title{
CORRESPONDENCE
}

\section{Postoperative Cognitive Dysfunction}

by PD Dr. med. Ingrid Rundshagen in issue 8/2014

\section{Cortisol Levels Are Key}

I would like to add three aspects to the most welcome review on postoperative cognitive dysfunction (POCD) by PD Dr. med. Ingrid Rundshagen (1).

Because of the significant association between increased interleukin- 6 and $S 100 \beta$ protein levels and the development of POCD (2), these basic proinflammatory markers could be used for POCD screening in a clinical setting. Likewise, the pre-operative ratio of the Alzheimer biomarkers beta-amyloid (1-42) and tau protein in the cerebrospinal fluid (CSF) appears to be of relevant predictive value as it is associated with the incidence of POCD (3).

Cortisol levels should be measured pre- and postoperatively to determine the direct pathogenic effect of stress on cognitive performance, as it has been shown that immediately after surgery, patients with POCD have significantly increased cortisol levels compared to patients without post-operative deficits (4). Future research should also explore other factors which may play a role in POCD, such as ubiquitin C-terminal hydrolase L1, body weight or the number of units of blood transfused perioperatively.

DOl: 10.3238/arztebl.2014.0424a

\section{REFERENCES}

1. Rundshagen I: Postoperative cognitive dysfunction. Dtsch Arztebl Int 2014; 111: 119-25

2. Peng $L, X u L$, Ouyang $W$ : Role of peripheral inflammatory markers in postoperative cognitive dysfunction (POCD): a meta-analysis. PLOS One 2013; 8: e79624.

3. Xie Z, McAuliffe S, Swain CA, et al.: Cerebrospinal fluid a $\beta$ to tau ratio and postoperative cognitive change. Ann Surg 2013; 258 364-9.

4. Mu DL, Li LH, Wang DX, et al.: High postoperative serum cortisol level is associated with increased risk of cognitive dysfunction early after coronary artery bypass graft surgery: a prospective cohort study. PLoS One 2013; 8: e77637.

Dr. oec. troph. Martin Hofmeister

Verbraucherzentrale Bayern e.V.

Referat Lebensmittel und Ernährung

München, Germany

hofmeister@vzbayern.de

\section{In Reply}

Dr. Hofmeister draws attention to a recently published paper on the association between biomarkers (interleukin 6, S100 $\beta$ protein, cortisol, etc.) and POCD.

Although these approaches are very interesting from a scientific perspective, it is my view that none of the named markers is suitable for use as a clinical screening instrument. It would be welcome to have a preoperative screening tool to identify patients with an increased risk for POCD. In the publications mentioned, pre-operative baseline levels were often not determined; thus, it has not yet been possible to define a critical threshold value. Due to significant inter- and intra-individual variations and the fact that a clearly defined quantitative relationship with regard to the results of cognitive function tests still needs to be established, these markers are not yet suitable for post-operative screening to monitor recovery.

The cited paper of Xie et al. highlights the significance of subclinical cognitive impairments along with the development of dementia and the incidence of POCD. In this paper the biomarkers are derived from $\mathrm{CSF}$, limiting their use as a routine pre-operative screening tool.

Despite numerous very interesting approaches to studying POCD, our understanding of the condition remains poor. Especially for the development of potential therapeutic approaches further insights are needed

DOI: 10.3238/arztebl.2014.0424b

\section{REFERENCES}

1. Rundshagen I: Postoperative cognitive dysfunction. Dtsch Arztebl Int 2014; 111: 119-25.

PD Dr. med. Ingrid Rundshagen

Gemeinschaftspraxis Brahmsallee

Hamburg, Germany

ingrid.rundshagen@charite.de

\section{Conflict of interest statement}

PD Dr. Rundshagen has received fees for the preparation of scientific further education events from Abbott GmbH \& Co. KG (now AbbVie Deutschland GmbH $\&$ Co. KG)

\section{Conflict of interest statement}

The author declares that no conflict of interest exists. 